JOURNAL

of Health Inequalities

\title{
A public health perspective on combating youth e-cigarette use while aiming at the bull's eye: the end of combustible tobacco use
}

\author{
Clifford E. Douglas
}

American Cancer Society, United States

ADDRESS FOR CORRESPONDENCE: Prof. Clifford E. Douglas, American Cancer Society, 250 Williams Str., Atlanta, GA 30303, United States, e-mail: cliff.douglas@cancer.org

Supplementary materials (slides) are available in Webappendix 5 at the journal's website: https://www.termedia.pl/Journal/Journal_of_ Health_Inequalities-100.

It is critical, in the increasingly complex world of tobacco control, that advocates, scientists, and clinicians maintain a clear focus on the bull's eye of the tobacco control target: ending cigarette smoking, or combustible tobacco use. We published the American Cancer Society Public Health Statement on Eliminating Combustible Tobacco Use in the United States in the journal Cancer in June 2018 [1]. That guidance document states: "Eliminating cancer caused by tobacco use is the highest public health priority of the American Cancer Society. Cigarette smoking is the leading cause of cancer mortality in the United States, accounting for as much as $98 \%$ of all tobacco-related deaths".

Previously, in February 2018, we published the American Cancer Society Position Statement on Electronic Cigarettes [2], which counsels "that clinicians support all attempts to quit the use of combustible tobacco and work with smokers to eventually stop using any tobacco product, including e-cigarettes". It recognises that "Some smokers, despite firm clinician advice, will not attempt to quit smoking cigarettes and will not use FDA approved cessation medications". It further advises, based on a comprehensive review of the scientific evidence that we published in 2017 [3], that "These individuals should be encouraged to switch to the least harmful form of tobacco product possible; switching to the exclusive use of e-cigarettes is preferable to continuing to smoke combustible products". It also concludes that "these individuals should be regularly advised to completely quit using all tobacco products".

Since the release of our position statement on e-cigarettes, the controversy surrounding these products has grown, due largely to the rapid increase in youth vaping in the US. An additional consequence of this increased focus on e-cigarettes and youth is that the exponentially larger impact of combustible cigarette smoking on public health receives disproportionately little attention, seldom earning the headlines that the leading cause of preventable death deserves. This shortchanges public understanding and public health.

The American Cancer Society's statements are particularly focused on the US and may not necessarily apply elsewhere. Different countries face a wide variety of circumstances, product variations, and industry strategies, as well as different regulatory systems. But it is clear that today some experts and advocacy organisations, both in my country and others, neglect to remind the public of how bad smoking really is.

Industry marketing and product engineering techniques have created a troubling increase in underage e-cigarette use in the US, but we must still search for the right combination of regulatory and educational approaches to ensure that as few children as possible are enticed to use addictive e-cigarettes while protecting the harm reduction potential of a well-regulated e-cigarette industry. While we work on finding the right balance as effectively 
as we can, we must simultaneously reinforce a sense of proportionality when it comes to the leading preventable cause of death in our society, which is still cigarette smoking - the bull's eye on the tobacco control target.

Key words: tobacco control, e-cigarettes, public health, combustible tobacco, smoking, nicotine.

\section{DISCLOSURE}

The author reports no conflict of interests.

\section{References}

1. Douglas CE, Henson R, Drope J, Wender RC. The American Cancer Society public health statement on eliminating combustible tobacco use in the United States. CA Cancer J Clin 2018; 68: 240-245.

2. American Cancer Society. American Cancer Society Position Statement on Electronic Cigarettes. February 2018. Available from: https://www.cancer.org/healthy/ stay-away-from-tobacco/e-cigarette-position-statement. html (accessed: 14 May 2019).

3. Drope J, Cahn Z, Kennedy R, et al. Key issues surrounding the health impacts of electronic nicotine delivery systems (ENDS) and other sources of nicotine. CA Cancer J Clin 2017; 67: 449-471. 